\title{
A NEW INTERPRETATION OF THE WILSON EQUATION, AS A SHORT-CUT FORM OF THE ASSOCIATED SOLUTION THEORY*
}

\author{
TOMOSHIGE NITTA AND TAKASHI KATAYAMA \\ Department of Chemical Engineering, Faculty of Engineering Science, Osaka University, Toyonaka
}

\section{Introduction}

The Wilson equation proposed in $1964^{7}$ ) has attracted special interest because it can represent better the excess free energies for multi-component miscible systems composed of complex liquids than do the equations hitherto in use. The concept of "local volume fraction" suggested in the derivation of the Wilson equation has stimulated many researchers to propose some new expressions, such as the HeilPrausnitz ${ }^{2)}$, NRTL ${ }^{5)}$ and Bruin-Prausnitz ${ }^{1)}$ equations.

However, the derivation of the Wilson equation contains arbitrary steps and the concept of local fraction is ambiguous: it has no basis in the framework of statistical thermodynamics.

This paper suggests that the Wilson equation is derived from a short-cut form of the athermal associated solution theory and that therefore the Wilson equation is regarded as one of chemical theory.

\section{Theory}

If monomers and associated complexes in a solution obey the Flory-Huggins equation, the activity coefficient of $k$ component is given ${ }^{3)}$ by

$$
\ln \gamma_{k}=\ln \left(\frac{\Phi_{k_{1}}}{x_{k} \Phi_{k_{1}}^{0}}\right)+\left(\frac{1}{\chi_{k}^{0}}-\frac{v_{k}}{v} \cdot \frac{1}{\chi}\right)
$$

The excess free energy $g^{E}$ is

$$
\frac{g^{E}}{R T}=\sum_{i} x_{i} \ln \left(\frac{\Phi_{i_{1}}}{x_{i} \Phi_{i_{1}}^{0}}\right)+\left(\sum_{i} \frac{x_{i}}{\chi_{i}^{0}}-\frac{1}{\chi}\right)
$$

The expressions of $\Phi_{i_{1}}$ and $\chi$ are obtained by solving the molecular balance equations which essentially depend upon the association model assumed for the system. However, the exact solutions of the equations are restricted only to the cases of simplified association models. This situation limits the applicability of the associated solution theory.

Any appropriate equations of analytical form are desirable to approximate both $\Phi_{i_{1}}$ and $\chi$ for complex

\footnotetext{
* Received on March 18, 1974

干560 豊中市待兼山町1-1

大阪大学基礎工学部化学工学科 新田友茂

** The expression of Eq. (1) differs slightly from that of Kehiaian et al., who used the "true" mole fraction instead of the average degree of association in Eq. (1).
}

systems. The simplest approach may be to neglect the second term on the right-hand side of Eq. (2) (not of Eq. (1)) and to introduce any suitable analytical equations for the first term, because the second term usually contributes less than the first term. That is,

$$
g^{E} / R T=\sum_{i} x_{i} \ln \left(\frac{\Phi_{i_{1}}}{x_{i} \Phi_{i_{1}}^{0}}\right)
$$

Consider the case where the monomer volume fraction $\Phi_{i_{1}}$ is given by Eq. (4).

$$
\Phi_{i_{1}}=\frac{\Phi_{i}}{\sum_{j} \Phi_{j}\left(1+\eta_{i j}\right)}
$$

where $\eta$ is a constant corresponding to the association constant. If $\eta_{i j}=0$, there is no association between molecules of $i$ and $j$. The ratio of monomer volume fractions of $i$ component in the mixture and in pure liquid, $\Phi_{i_{1}} / \Phi_{i_{1}}^{0}$, is obtained as

$$
\frac{\Phi_{i_{1}}}{\Phi_{i_{1}}^{0}}=\frac{\Phi_{i}\left(1+\eta_{i i}\right)}{\sum_{j} \Phi_{j}\left(1+\eta_{i j}\right)}
$$

This is the same equation as the "local volume fraction" $\xi_{i}$ defined by Wilson ${ }^{7)}$.

$$
\xi_{i}=\frac{\Phi_{i} \exp \left(-\lambda_{i i} / R T\right)}{\sum_{j} \Phi_{j} \exp \left(-\lambda_{i j} / R T\right)}
$$

Therefore we obtain the following correspondence.

$$
\frac{\left(1+\eta_{i j}\right)}{\left(1+\eta_{i i}\right)} \leftrightarrow \exp \left(-\frac{\lambda_{i j}-\lambda_{i i}}{R T}\right)
$$

Clearly, the Wilson equation for the excess Gibbs energy is obtained by substituting Eq. (5) to Eq. (3) and by using the corresponding relation. The local volume fraction is replaced by the ratio of monomer volume fractions in this derivation.

\section{Discussion}

Wiehe and Bagley $^{6}$ derived the following expression of monomer volume fraction of A component which is assumed to be continuously selfassociated.

$$
\Phi_{A_{1}}=\frac{\Phi_{A}}{1+K_{A}^{(\phi)} \Phi_{A}}=\frac{\Phi_{A}}{\Phi_{A}\left(1+K_{A}^{(\Phi)}\right)+\sum_{\alpha} \Phi_{\alpha}}
$$




$$
K_{A}^{(\Phi)}=\Phi_{A_{i}} / \Phi_{A_{i-1}} \Phi_{A_{1}}
$$

Therefore, the monomer volume fraction in the Wiehe-Bagley equation is considered a special case of Eq. (4), that is

$$
\eta_{A A}=K_{A}^{(\Phi)} \text { and } \eta_{\alpha \beta}=0 \quad(\alpha \beta \neq \mathrm{AA})
$$

Wiehe and Bagley have already pointed out the similarities between the Wilson equation and the Wiehe-Bagley equation in their paper $^{6)}$. The difference between these equations is attributed to the difference between Eqs. (2) and (3). For systems of alcohol - saturated hydrocarbons both the Wilson and the Wiehe-Bagley equations have been found to be excellent. This may show that Eq. (4) of the monomer volume fraction is a proper one for the systems and that the contribution of the monomer volume fraction term to $g^{E}$ is predominant.

It is known that the Wilson equation cannot express phase separation behavior of liquid mixtures. To overcome this defect from the standpoint of the associated solution theory, addition of the physical interaction term to Eq. (3) may be useful ${ }^{4}$.

$$
\frac{g^{E}}{R T}=\sum_{i} x_{i} \ln \left(\frac{\Phi_{i_{1}}}{x_{i} \Phi_{i_{1}}^{0}}\right)+\frac{\left(\sum_{l} v_{l} x_{l}\right)}{R T} \sum_{i>j} b_{i j} \Phi_{i} \Phi_{j}
$$

If Eq. (4) is applied to $\Phi_{i_{1}}$, the activity coefficient of $k$ component $\ln \gamma_{k}$ is given by Eq. (10).

$$
\begin{aligned}
\ln \gamma_{k}= & -\ln \left[\sum_{j} x_{j} \Lambda_{k j}\right]+1-\sum_{i} \frac{x_{i} \Lambda_{i k}}{\sum_{j} x_{j} \Lambda_{i j}} \\
& +\frac{v_{k}}{R T} \sum_{i} \sum_{j} \Phi_{i} \Phi_{j}\left[b_{i k}-\frac{1}{2} b_{i j}\right]
\end{aligned}
$$

where

$$
\Lambda_{i j}=\frac{\left(1+\eta_{i j}\right)}{\left(1+\eta_{i i}\right)} \cdot \frac{v_{j}}{v_{i}}
$$

\section{Conclusion}

It was shown that the Wilson equation is regarded as a special solution obtained from a short-cut form of the athermal associated solution theory and that the concept of the "local volume fraction" may be replaced by the term of the ratio of the monomer volume fractions (in the mixture and in pure liquid). To express the phase separation behavior of a liquid mixture, Eq. (10) is suggested. This is a combination of the Wilson equation with the Scatchard-Hildebrand equation.

$$
\begin{aligned}
& \text { Nomenclature } \\
& b_{i j} \quad=\text { physical interaction parameter for } i-j \text { pair [cal } / \mathrm{cc} \text { ] } \\
& \left.g^{E} \quad=\text { excess Gibbs free energy [cal } / \mathrm{mole}\right] \\
& K_{A}^{(\phi)} \quad=\text { self-association constant on volume fraction } \\
& \text { basis for component A [-] } \\
& R=\text { gas constant } \quad\left[\mathrm{cal} / \mathrm{mole} \cdot{ }^{\circ} \mathrm{K}\right] \\
& T \quad=\text { absolute temperature } \quad\left[{ }^{\circ} \mathrm{K}\right] \\
& v \quad=\text { molar volume [cc/mole] } \\
& x \quad=\text { mole fraction } \quad[-] \\
& \gamma \quad=\text { activity coefficient } \quad[-] \\
& \begin{aligned}
\eta_{i j}= & \text { constant corresponding to association } \\
& \text { constant for } i-j \text { pair }
\end{aligned} \\
& \chi \quad=\text { average degree of association } \\
& \text { (=number of stoichiometric moles/ } \\
& \text { number of true moles) [-] } \\
& \chi_{i}^{0}=\text { average degree of association }(\chi) \text { in pure } \\
& \text { liquid } i \quad \text { [-] } \\
& \Phi_{i} \quad=\text { volume fraction of component } i \quad[-] \\
& \Phi_{i_{1}} \quad=\text { volume fraction of monomer of component } i[-] \\
& \Phi_{i 1}^{0} \quad=\text { volume fraction of monomer }\left(\Phi_{i_{1}}\right) \text { in pure } \\
& \text { liquid } i \quad \text { [-] } \\
& \xi \quad=\text { local volume fraction } \quad[-] \\
& \lambda_{i j} \quad=\text { Wilson energy parameter for } i-j \text { pair } \quad[\mathrm{cal} / \mathrm{mole}] \\
& \Lambda_{i j} \quad=\text { Wilson parameter [-] } \\
& \langle\text { Subscripts〉 } \\
& i, j, k, \ldots=\text { components of } i, j, k, \ldots, \text { respectively } \\
& A_{i} \quad=\text { associated } i \text {-mer of component A }
\end{aligned}
$$

\section{Literature Cited}

1) Bruin, S. and J. M. Prausnitz: Ind. Eng. Chem., Process Des. Develop., 10, 562 (1971)

2) Heil, J. F. and J. M. Prausnitz: AIChE J., 12, 678 (1966)

3) Kehiaian, H. and A. Treszczanowicz: Bull. Acad. Pol. Sci. Ser. sci. chim., 14, 891 (1966)

4) Nitta, T. and T. Katayama: J. Chem. Eng. Japan, 6, 1 (1973)

5) Renon, H. and J. M. Prausnitz: AIChE J., 14, 135 (1968)

6) Wiehe, I. A. and E. B. Bagley: Ind. Eng. Chem., Fundam., 6, 209 (1967)

7) Wilson, G. M.: J. Am. Chem. Soc., 86, 127 (1964) 